\title{
Genome-wide association analysis reveals new targets for carotenoid biofortification in maize
}

\author{
Willy B. Suwarno $\cdot$ Kevin V. Pixley • \\ Natalia Palacios-Rojas $\cdot$ Shawn M. Kaeppler • \\ Raman Babu
}

Received: 24 August 2014 / Accepted: 4 February 2015 / Published online: 18 February 2015

(C) The Author(s) 2015. This article is published with open access at Springerlink.com

\begin{abstract}
Key message Genome-wide association analysis in CIMMYT's association panel revealed new favorable native genomic variations in/nearby important genes such as hydroxylases and CCD1 that have potential for carotenoid biofortification in maize.

Abstract Genome-wide association studies (GWAS) have been used extensively to identify allelic variation for genes controlling important agronomic and nutritional traits in plants. Provitamin A (proVA) enhancing alleles of lycopene epsilon cyclase (LCYE) and $\beta$-carotene hydroxylase 1 (CRTRB1), previously identified through candidate-gene based GWAS, are currently used in CIMMYT's maize breeding program. The objective of this study was to identify genes or genomic regions controlling variation for carotenoid concentrations in grain for CIMMYT's carotenoid association mapping panel of 380 inbred maize lines,
\end{abstract}

Communicated by J. Yan.

Electronic supplementary material The online version of this article (doi:10.1007/s00122-015-2475-3) contains supplementary material, which is available to authorized users.

W. B. Suwarno

Department of Agronomy and Horticulture, Faculty

of Agriculture, Bogor Agricultural University, Jl. Meranti

Kampus IPB Dramaga, Bogor 16680, Indonesia

K. V. Pixley $\cdot$ N. Palacios-Rojas $\cdot$ R. Babu $(\square)$

International Maize and Wheat Improvement Center (CIMMYT),

Km 45 Carretera Mexico-Veracruz, Texcoco, Mexico 56130,

Mexico

e-mail: r.babu@cgiar.org

S. M. Kaeppler

Department of Agronomy, University of Wisconsin-Madison,

1575 Linden Drive, Madison, WI 53705, USA using high-density genome-wide platforms with $\sim 476,000$ SNP markers. Population structure effects were minimized by adjustments using principal components and kinship matrix with mixed models. Genome-wide linkage disequilibrium (LD) analysis indicated faster LD decay (3.9 kb; $\left.r^{2}=0.1\right)$ than commonly reported for temperate germplasm, and therefore the possibility of achieving higher mapping resolution with our mostly tropical diversity panel. GWAS for various carotenoids identified CRTRB1, $L C Y E$ and other key genes or genomic regions that govern rate-critical steps in the upstream pathway, such as $D X S 1$, GGPS1, and GGPS2 that are known to play important roles in the accumulation of precursor isoprenoids as well as downstream genes $H Y D 5, C C D 1$, and $Z E P 1$, which are involved in hydroxylation and carotenoid degradation. SNPs at or near all of these regions were identified and may be useful target regions for carotenoid biofortification breeding efforts in maize; for example a genomic region on chromosome 2 explained $\sim 16 \%$ of the phenotypic variance for $\beta$-carotene independently of CRTRB1, and a variant of $C C D 1$ that resulted in reduced $\beta$-cryptoxanthin degradation was found in lines that have previously been observed to have low proVA degradation rates.

$\begin{array}{ll}\text { Abbreviations } \\ \text { LUT } & \text { Lutein } \\ \text { ZEA } & \text { Zeaxanthin } \\ \text { L:Z } & \text { Lutein:zeaxanthin ratio } \\ \beta C X & \beta \text {-cryptoxanthin } \\ \beta C & \beta \text {-carotene } \\ \text { proVA } & \text { Total provitamin A } \\ \text { GBS } & \text { Genotyping-by-sequencing } \\ \text { LD } & \text { Linkage disequilibrium } \\ \text { FELM } & \text { Fixed effect linear model } \\ \text { MLM } & \text { Mixed linear model }\end{array}$




\begin{tabular}{|c|c|}
\hline MAF & Minor allele frequency \\
\hline MEP & Methyl-erythriol 4-phosphate \\
\hline DMAPP & Dimethylallyl diphosphate \\
\hline IPP & Isopenthyl diphosphate \\
\hline GGPP & Geranyl geranyl pyrophosphate \\
\hline DXS & 1-deoxy-D-xtylulose-5-phosphate \\
\hline DXR & $\begin{array}{l}\text { Deoxy-D-xtylulose-5-phosphate } \\
\text { reductoisomerase }\end{array}$ \\
\hline HDS & $\begin{array}{l}\text { 4-hydroxy-3-methylbut-2-en-1-yl diphosphate } \\
\text { synthase }\end{array}$ \\
\hline IDR & $\begin{array}{l}\text { 4-hydroxy-3-methylbut-2-en-1-yl diphosphate } \\
\text { synthase }\end{array}$ \\
\hline HDR & $\begin{array}{l}\text { 4-hydroxy-3-methylbut-2-en-1-yl diphosphate } \\
\text { reductase }\end{array}$ \\
\hline GGPS & Geranyl geranyl pyrophosphate synthase \\
\hline PSY & Phytoene synthase \\
\hline PDS & Phytoene desaturase \\
\hline ISO & 15-cis-zeta carotene isomerase \\
\hline ZDS & $\zeta$-carotene desaturase \\
\hline CRTISO & Carotenoid isomerase \\
\hline LCYE & Lycopene epsilon cyclase \\
\hline LCYB & Lycopene beta cyclase \\
\hline CRTRB1 & $\beta$-carotene hydroxylase \\
\hline CCD1 & Carotenoid cleavage dioxygenase 1 \\
\hline ZEP & Zeaxanthin epoxidase \\
\hline 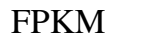 & Fragments per kilo base per million reads \\
\hline
\end{tabular}

\section{Introduction}

Maize is one of the three most important staple food grains worldwide and is a source of calories, protein, vitamins, and minerals in the diets of 300 million inhabitants of sub-Saharan Africa, Latin America and some parts of Asia. While the annual per capita food maize consumption in these regions averages 36,23 , and $10 \mathrm{~kg}$, respectively, it exceeds $100 \mathrm{~kg}$ in several countries (Atlin et al. 2011). Maize-based diets tend to be deficient in the important micronutrients provitamin A (proVA), iron and zinc, and over-dependence of people on maize-based diets may result in poor health including stunted growth, reduced capacity for physical activity, and in extreme cases, high incidence of anemia, corneal blindness, compromised immunity and infant morbidity (Saltzman et al. 2013).

Most yellow maize grown and consumed throughout the world, however, has less than $2 \mu \mathrm{g} \mathrm{g}^{-1}$ of proVA (Pixley et al. 2013). Biofortification of maize grains with high levels of proVA carotenoids is a promising solution to overcome vitamin A malnutrition (Graham et al. 2001; Saltzman et al. 2013). ProVA maize breeding is led by the International Maize and Wheat Improvement Center
(CIMMYT) and the International Institute of Tropical Agriculture (IITA) in collaboration with public- and privatesector research partners in Southern Africa and supported by the HarvestPlus Challenge Program (www.harvestplus. org). In 2012, proVA breeding efforts resulted in the release of three maize hybrids in Zambia and two in Nigeria with total proVA carotenoid concentrations of more than 7 $\mu \mathrm{g} \mathrm{g}^{-1}$, and experimental cultivars with $10-15 \mu \mathrm{g} \mathrm{g}^{-1}$ have been identified (Dhliwayo et al. 2014; Saltzman et al. 2013; Suwarno et al. 2014).

The carotenoid biosynthetic pathway is well studied and the enzymes involved in carotenogenesis are documented in maize and other species (Giuliano et al. 2008; Li et al. 2009). Considerable diversity exists in the regulation of synthesis and catabolism of carotenoids (Auldridge et al. 2006; Vallabhaneni et al. 2010; Arango et al. 2014) (Fig. S1). In addition to biosynthesis and catabolism (enzymatic degradation), other factors like non-enzymatic degradation (oxidation, photo and thermal degradation), sequestration and intracellular localization of carotenoids influence their accumulation. Although knowledge of the mechanisms regulating carotenoid content and composition is increasing (Shumskaya and Wurtzel 2013; De Moura et al. 2013), it is still incomplete. Studies of carotenoid content and composition in maize grains have identified significant allelic variation for key genes such as lycopene epsilon cyclase (LCYE) (Harjes et al. 2008) and $\beta$-carotene hydroxylase 1 (CRTRB1) (Yan et al. 2010) that govern critical steps in the pathway, leading to the successful use of marker-assisted selection (MAS) in applied breeding programs (Babu et al. 2013).

Discovery efforts to understand key genes involved in natural variation for carotenoid content have used genome-wide association (GWAS) approaches to explore allelic variation at loci previously established to be associated with the carotenoid pathway in maize or other model species (Harjes et al. 2008; Vallabhaneni et al. 2009; Yan et al. 2010). With the onset of high-density genotyping platforms, like Illumina's infinium (MaizeSNP50 at http:// res.illumina.com) and genotyping by sequencing (GBS) (Elshire et al. 2011), it is now possible to quickly generate millions of marker data points that are distributed throughout the genome. GWAS based on high density, extensive marker coverage increases our ability to explain the inheritance of target traits (Gibson 2010; Stranger et al. 2011).

Our objective was to use high-density marker platforms to identify allelic variation that influences total and component carotenoids concentrations in grain for CIMMYT's maize carotenoid association mapping (CAM) panel comprised of 380 diverse tropical, subtropical and temperate inbred lines. 


\section{Materials and methods}

\section{Phenotype data}

The carotenoids association mapping (CAM) panel consisted of 380 diverse lowland tropical $(47 \%)$, subtropical $(47 \%)$ and temperate $(3 \%)$ lines assembled by CIMMYT's HarvestPlus-funded maize breeding program. The panel includes 10 lines in which a proVA-enhancing allele of CRTRB1 has been incorporated through marker-assisted selection (Babu et al. 2013). The CAM panel was grown in three environments-summer 2010 (TL10) and summer 2011 (TL11) at Tlaltizapan, Morelos, Mexico, and summer 2012 (AF12) at Agua Fria, Puebla, Mexico. Tlaltizapan is located at $18^{\circ} 41^{\prime} \mathrm{N}, 99^{\circ} 07^{\prime} \mathrm{W}, 945 \mathrm{~m}$ above sea level (masl), and has average annual temperature of $23.5{ }^{\circ} \mathrm{C}$ and average annual precipitation of $840 \mathrm{~mm}$. Agua Fria is located at $20^{\circ} 32^{\prime} \mathrm{N}, 97^{\circ} 28^{\prime} \mathrm{W}, 110$ masl, and has average annual temperature of $22^{\circ} \mathrm{C}$ with average annual precipitation of 1,200 mm. Field plots were single, $5 \mathrm{~m}$ long rows with about 26 plants, and were unreplicated at Tlaltizapan and had two replications at Agua Fria. Two to six plants in each plot were self-pollinated and ears were collected at harvest maturity. Kernels were bulked for subsequent carotenoid analyses.

Carotenoid analyses were conducted at CIMMYT's maize quality laboratory, Mexico. Random samples of 50 seeds were kept frozen at $-80{ }^{\circ} \mathrm{C}$ until being ground to a fine powder $(0.5 \mu \mathrm{m})$, followed by the CIMMYT laboratory protocols for carotenoids analysis, including extraction, separation, and quantification by HPLC for TL10 and TL11 environments (Galicia et al. 2008), and by UPLC for AF12 (Galicia et al. 2012). Only the separation procedure varied between the two methods, such that the HPLC method allowed better resolution for the xanthophylls (lutein and zeaxanthin) as compared to the UPLC. Lutein (LUT), zeaxanthin (ZEA), $\beta$-cryptoxanthin $(\beta C X), \beta$-carotene $(\beta C)$, and total proVA concentrations (proVA $=\beta C+0.5(\beta C X)$ ) were measured and reported in $\mu \mathrm{g} \mathrm{g}^{-1}$ of kernel dry weight.

\section{Genotype data}

Genotype data were generated through two platforms, $55 \mathrm{~K}$ (56,110 SNPs) and GBS v2.7 (954,179 SNPs); we used both platforms to benefit from the additional power that this might offer. The $55 \mathrm{~K}$ genotyping utilized the MaizeSNP50 Genotyping BeadChip from Illumina (catalog is available at www.illumina.com) and was carried out at the Syngenta facility, Slater, IA, USA, and the GBS genotyping was conducted at the Institute for Genomic Diversity, Cornell University, Ithaca, NY, USA. The physical coordinates of GBS and $55 \mathrm{~K}$ SNPs are derived from AGPv2. Based on the twin criterion of Call Rate $(>0.85$ for $55 \mathrm{~K}$ and $>0.3$ for GBS) and Minor Allele Frequency (MAF) ( $>0.05$ for $55 \mathrm{~K}$ and $>0.02$ for GBS), we selected 39,846 SNPs from the $55 \mathrm{~K}$ chip and 435,975 SNPs from the GBS. We adopted different CR and MAF criterion for GBS and $55 \mathrm{~K}$ data owing to the nature of the genotyping platform and the ability to uncover the rare alleles. The $55 \mathrm{~K}$ dataset had less than $5 \%$ missing datapoints and hence did not require imputation. On the contrary, the GBS dataset originally had close to $40 \%$ of the datapoints missing. The GBS service provider (Institute of Genomic Diversity, Cornell University) performed a partial imputation based on an algorithm that searched for the closest neighbor in small SNP windows across the entire maize database (approximately 22,000 Zea samples), allowing for a $5 \%$ mismatch (Romay et al. 2013). If the requirements were not met, the SNP was not imputed. A previous study reported approximately $4 \%$ median discrepancy rates between actual and imputed calls in the Goodman association panel of maize (Romay et al. 2013). The partially imputed GBS data in our study contained $13 \%$ missing data. The partially imputed GBS data were combined with unimputed $55 \mathrm{~K}$ data for further analysis. For GWAS, we combined 'filtered 55 K' and 'filtered GBS', which resulted in a combined dataset of 475,821 SNPs. From this, a subset of high quality markers $(171,696$ SNPs with CR $>0.9$ and MAF $>0.1)$ was used for deriving PCA and kinship matrices. A large number of markers will provide greater opportunity for identifying significant associations in GWAS studies, whereas the use of the reduced marker set with less missing data and robust MAF was desirable for analysis of population structure and kinship.

\section{Statistical analysis}

Each carotenoid trait $(y)$ was transformed to $\log _{10}(y+1)$ to approach normality of residuals and equality of residual variances assumptions prior to performing analysis of variance. Distributions of phenotypic values before transformation are presented in Fig. S2. Best Linear Unbiased Estimators (BLUEs) obtained from the multi-location analyses were used in the GWAS. Pearson phenotypic correlation coefficients among carotenoid concentrations were calculated using inbred line means in $\log _{10}(\mathrm{y}+1)$ scale, and phenotypic correlation coefficients between environments were calculated to evaluate consistency of phenotypes across the three environments. ANOVA and correlation analyses were conducted using R software (R Core Team, 2012). $\log _{10}(y+1)$ scale was used because of the presence of zero values for some of the traits. The transformed mean values were used in the GWAS analyses.

The population structure was evaluated using the K-means clustering method using the 'adegenet' library in $\mathrm{R}$, and a principal component analysis (PCA) was 
performed in SNP and Variation Suite (SVS) v7.7.8 (SVS, Golden Helix, Inc., Bozeman, MT, www.goldenhelix. com). The first two PCA coordinates were used to visualize genetic distances among inbred lines, and the PCA results were then labeled using $\mathrm{K}$-means groupings of the lines. An estimated number of groups in the population was obtained based on Bayesian information criterion (BIC) values (Jombart et al. 2010), visual inspection of the PCA plot and pedigree information.

The extent of genome-wide and chromosome-wise linkage disequilibrium (LD) was evaluated based on adjacentpairwise $r^{2}$ values (the squared correlation coefficients among alleles at two adjacent SNP markers) and physical distances among these SNPs (Remington et al. 2001). Nonlinear models with $r^{2}$ as responses $(y)$ and pairwise distances $(x)$ as predictors were fitted into the genome-wide and chromosome-wise LD data using the 'nlin' function in R. Average pairwise distances in which LD decayed at $r^{2}=0.2$ and $r^{2}=0.1$ were then calculated based on the model. The expected value of $r^{2}$ was:

$E\left(r^{2}\right)=\left[\frac{10+C}{(2+C)(11+C)}\right]\left[1+\frac{(3+C)\left(12+12 C+C^{2}\right)}{n(2+C)(11+C)}\right]$

where $r^{2}=$ squared correlation coefficient, $n=$ sample size, and $\mathrm{C}$ is a model coefficient for the distance variable (Hill and Weir 1988).

Ten principal components from the PCA as obtained by SVS v7.7.8 were used as covariates in the linear models for GWAS analyses. The PCA was performed using the method implemented in the EIGENSTRAT software, in which 10 principal components are recommended as a default value for population structure correction (Price et al. 2006). A kinship matrix was generated from identityby-state distances among inbred lines, calculated as:

IBS distance $=[$ No. of markers IBS $2+0.5 \times($ No. of markers IBS1)]/No. non-missing markers.

Where, IBS1 and IBS2 are the states in which the two inbred lines share one or two alleles, respectively, at a marker (Bishop and Williamson 1990). PCA and kinship analyses were carried out using SVS.

Individual SNP-based association tests were conducted using the correlation/trend method (Weir 2008) using SVS. Two association mapping models were used:

$\mathrm{Y}=\mathrm{SNP} \times \beta+\mathrm{PC} \times \alpha+\varepsilon$ (Fixed effect linear model, FELM).

$\mathrm{Y}=\mathrm{SNP} \times \beta+\mathrm{PC} \times \alpha+\mathrm{K}+\varepsilon$ (Mixed linear model, MLM).

Where, $Y=$ response of the dependent variable (means of carotenoids phenotypes across environments), $\mathrm{SNP}=\mathrm{SNP}$ marker (fixed effects), $\mathrm{PC}=$ principal component coordinate from the PCA (fixed), $K=$ kinship matrix (random), and $\alpha$ and $\beta$ are SNP and PC fixed effect model coefficients, respectively. Traits included in the association mapping analyses were $\beta C, \beta C X$, ZEA, and LUT:ZEA ratio (L:Z). Another association analysis for $\beta C$ was performed using the most significant SNP as a covariate. The phenotypic values $(y)$ were transformed to $\log _{10}(y+1)$ scale for all traits.

Association mapping model evaluations were based on visual observation of the quantile-quantile (Q-Q) plots, which are the plots of observed $-\log 10 P$ values versus expected $-\log 10 P$ values under the null hypothesis that there is no association between marker and the phenotype. In this study, we devised two different approaches of identifying GWAS signals. The first approach is that of solely based on smallest $P$ values obtained from mixed linear models, where the SNPs were ranked based on their ascending order of MLM- $P$ values (smallest on top), top 40-50 SNPs were selected for each trait, grouped into $500 \mathrm{~kb}$ chromosome segments and then the most significant SNP in each of the top 5-10 genomic regions was identified. This approach was effective in identifying the significant associations but frequently ignored SNPs whose minor allele is not prevalent (MAF values in the range of $0.02-0.05$ ) in the association panel but included for GWAS analyses. One of the unique and significant aspects of this study is the high-density GBS genotype data, which uncovered large number of rare alleles as compared to $55 \mathrm{~K}$ chip data which mostly detected common SNP alleles. Hence we adopted a second approach in which, we identified significant rare allele associations based on multiple criterion such as phenotype average for homozygous-minor-allele genotype (DD) greater (for $\beta \mathrm{C}, \beta C X, \mathrm{ZEA}$ ) or lower (for $\mathrm{L}: Z$ ) than overall mean, number of DD lines $\geq 8$ ( $2 \%$ of the population), FELM and MLM $P$ values $<0.01$. Since the phenotype means of the minor allele are typically based on smaller number of individuals, the statistical power of this approach is limited but nevertheless was useful in identifying smaller number of candidate signals for further validation in specific bi-parental populations. Fifty markers identified based on the above-mentioned criterion were grouped into $500 \mathrm{~kb}$ chromosome segments, and the most significant SNP in each of the top 5-10 regions was identified for each trait. It is to be noted that the physical positions of GBS-SNPs are based on B73 sequence and considering the pronounced genome non-collinearity among different maize germplasm (Xu and Messing 2006), we considered broader intervals (up to $2.5 \mathrm{Mb}$ ) while searching for carotenoid-related nearby genes (Table S2) in the vicinity of most significant associations.

The phenotypic difference between two homozygote classes of a given significant SNP for each of the carotenoid trait is presented as effect size, which is not corrected for population structure or kinship. To estimate the proportion of phenotypic variation explained by a combination of 
Fig. 1 Principal coordinate analysis plot based on the $\mathrm{GBS}+55 \mathrm{~K}$ data, color-labeled based on the K-means clustering results. Black, red, and green color represent group 1 (tropical heterotic group B lines), 2 (provitamin A source lines), and 3 (tropical heterotic group A lines), respectively

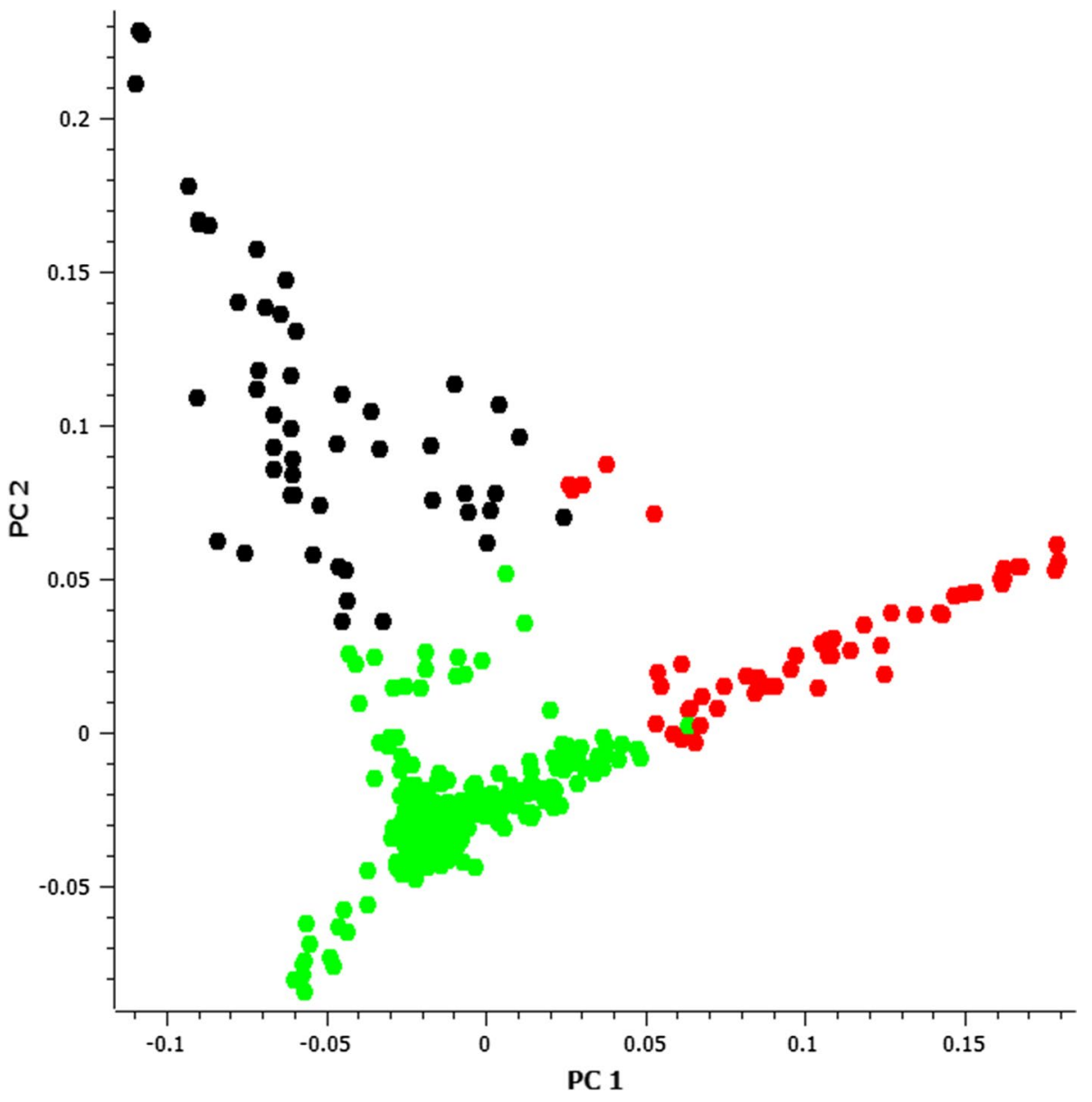

candidate SNPs, a multiple linear regression for each trait was performed using phenotype values as a response variable $(y)$ and candidate SNPs as predictors $(x)$. Best marker combinations in the model were then inferred by a stepwise selection procedure based on Akaike information criterion (AIC), using the 'step' function in R.

\section{Results}

Analyses of variance and correlations

There was significant variation among inbred lines for all carotenoids $(P<0.01)$ (data not shown). The broad-sense heritability estimates were high and ranged from 0.89 to 0.93 in the multi-location analyses for various carotenoid traits (LUT-0.89, ZEA-0.93, L:Z-0.92, Bcx-0.91, $\beta C-0.92$ and ProVA-0.93). Pearson correlation coefficients among carotenoid concentrations were mostly significant $(P<0.01)$, except for LUT with $\beta C X, \beta C$, and proVA (Table S3). Strong correlations $(r \geq 0.60)$ were observed between $\beta C X$ and ZEA, and for proVA with $\beta C X$ and $\beta C$. Correlation coefficients among environments for each trait were significantly large $(r>0.75, P<0.01)$ except for AF12 (UPLC) with TL10 and TL11 (HPLC) for LUT, indicating that the carotenoid phenotypes were generally consistent across environments (Table S4). We used HPLC data for LUT and the combined (HPLC and UPLC) data for all other component carotenoids in the association analyses. Though UPLC and HPLC values largely agreed with each other in general, we observed some discrepancy particularly for LUT. One of the possible reasons for this is that the extraction and separation protocols are optimized for higher recovery of provitamin A carotenoids $(\beta C X$ and $\beta C)$ as compared to LUT and ZEA.

Population structure and linkage disequilibrium

The population structure among the 380 lines was well described by the K-means clustering method (Fig. 1), where BIC model selection and visual observation of the PCA plot indicated that three clusters were most likely for this population. Group 1 (Fig. 1, colored in black) consisted of 49 lines that predominantly belonged to CIMMYT's tropical germplasm of heterotic group B, group 3 (green) contained 277 lines from CIMMYT's tropical germplasm 
of heterotic group A, and group 2 (red) included 54 lines which were mostly source germplasm for enhanced proVA content and included introgression of tropical or temperate germplasm that is exotic to CIMMYT's breeding program. Proportions of phenotypic variation explained by this population structure alone were $24 \%$ for $\beta C, 17 \%$ for $\beta C X$, $8 \%$ for ZEA, and $10 \%$ for L:Z.

Average physical distance between pairs of markers was $14.1 \mathrm{~kb}$ and the average genome-wide LD $\left(r^{2}\right)$ obtained based on adjacent pairs of markers was 0.41 . Genome-wide LD decay was $1.36 \mathrm{~kb}$ at $r^{2}=0.2$ and $3.89 \mathrm{~kb}$ at $r^{2}=0.1$ (Fig. S4). Chromosome-wise LD analyses showed that the slowest LD decay was observed on chromosome 8 $\left(8.19 \mathrm{~kb}, r^{2}=0.1\right)$, followed by chromosome $4(5.20 \mathrm{~kb}$, $\left.r^{2}=0.1\right)$, whereas the remaining chromosomes had very similar average distance of $3.55 \mathrm{~kb}$ at $r^{2}=0.1$

Correcting for population structure using either PCA or the kinship matrix was important to improve predictions relative to the model involving only genotypes (the $\mathrm{G}$ model). Using both PCA and the kinship matrix in the model $(\mathrm{G}+\mathrm{Q}+\mathrm{K}$ or MLM model) improved the accuracy further by eliminating more false positives in the association mapping results (Fig. S6).

\section{Association mapping}

The $55 \mathrm{~K}$ dataset had smaller proportion of SNPs with low minor allele frequency (MAF $<0.2=38 \%$ ) than the GBS $(58 \%)$ and the $55 \mathrm{~K}+\mathrm{GBS}(56 \%)$ datasets (Fig. S3). In the latter set, which was used for association mapping, markerfree intervals ranged from $1 \mathrm{bp}$ to $955.78 \mathrm{~kb}$ with a median of $30 \mathrm{bp}$, and SNP density was 1 SNP per $4.39 \mathrm{~kb}$. The CAM panel of 380 lines had an average heterozygosity rate of 0.06 , reflecting that most of these lines were either fixed or in advanced inbreeding generations. The panel included 12 QPM (quality protein maize) lines that have enhanced protein quality due to the presence of the homozygous recessive allele of the opaque2 gene (Atlin et al. 2011). Association analysis using the QPM trait as binary phenotype ( 0 for normal and 1 for QPM) rightly identified the ораque 2 gene on chromosome 7 , thereby validating our methods and statistical approach (Fig. 2).

Based on the mixed linear model (MLM) association analysis, significant genomic regions for each of the carotenoid component traits were identified based on smallest $P$ values as well as rare alleles of large effect sizes as described in materials and methods (Table 1).

Among the seven significant associations for $\beta$-carotene $(\beta C)$, four were located on chromosome 10 , and the most significant one (S10_135911532) was located near (vicinity of $500 \mathrm{~kb}$ ) the previously identified CRTRBI gene. Two other SNPs with significant $P$ values on chromosome 10 (S10_133820657 and S10_134655704) were also located in the vicinity of $C R T R B 1$, with large effect sizes $\left(\sim 11 \mu \mathrm{g} \mathrm{g}^{-1}\right)$ and small MAF (0.02-0.03), which was in line with our expectation as there were only 10 CRTRBI introgression lines in the panel. Interestingly, we found a genomic region on chromosome 2 (S2_212648728) associated with $\beta C$ concentrations after accounting for the variation explained by the most significant marker (S10_135911532/CRTRB1). This region was highlighted conspicuously by multiple significant SNPs in the Manhattan plot (Fig. 2), in which the most significant SNP in the region had an effect of $\sim 3 \mu \mathrm{g} \mathrm{g}^{-1}$ and explained close to $16 \%$ of phenotypic variance for $\beta C$. Rare allele analysis was conducted to identify genomic regions where minor alleles had favorable effects; however, rare allele analysis for $\beta C$ did not reveal any additional regions that were unrelated to CRTRB1. A linear multiple regression model with five most significant SNPs explained approximately $61 \%$ of the phenotypic variance for $\beta C(P<0.01$; Table 2$)$.

The most significant marker (S10_133820657) for $\beta$-cryptoxanthin $(\beta C X)$ was located in close proximity with $C R T R B 1$ and its minor allele frequency (0.02) matched with the number of CRTRBI introgression lines in the panel. The negative effect $\left(-2.27 \mu \mathrm{g} \mathrm{g}^{-1}\right)$ of this SNP was due to the negative correlation between $\beta C$ and $\beta C X$. A total of 13 genomic regions with favorable minor allele were identified, of which three were rare allele type (MAF $<0.05$ ). The effect sizes of significant SNPs ranged from 0.7 to $3 \mu \mathrm{g} \mathrm{g}^{-1}$, each explaining 2-6\% of phenotypic variance for $\beta C X$ (Tables 1 and 2). Four selected SNPs from $P$ value based association analysis explained close to $30 \%$ of phenotypic variance for $\beta C X$ concentration (Table 2).

A region represented by S2_16916669, located relatively close to the non-heme di-iron $\beta$-carotene hydroxylase gene HYDI (2: 15,865,938-15,868,219), and another by S9_151998412, located near both the carotenoid cleavage dioxigenase 1 CCD1 (9: 152,086,899-152,092,882) and HYD5 (9: 153,692,212-153,694,576), suggested possible roles for these candidate genes in influencing $\beta C X$ concentrations. A SNP, S6_146033807 uncovered by the rare allele analysis was located close to DXS1 gene which is involved in carotenoid metabolism.

The most significant marker (S2_44448492) for ZEA was located within the zeaxanthin epoxidase 1 (ZEPl) gene on chromosome $2(44,440,299-44,449,237)$. The SNP had MAF of 0.31 , phenotypic effect of $5.12 \mu \mathrm{g} \mathrm{g}^{-1}$, and explained $11 \%$ of the phenotypic variance for ZEA concentration. Seven other candidate SNPs from $P$ value based analysis had negative effects as well, indicating the prevalence of favorable alleles at most of the detected loci for ZEA in the CAM panel. Rare allele analysis revealed several candidate regions (on chromosomes 5, 7, and 10) associated with ZEA concentration. These SNPs had relatively large effect sizes, ranging from 5.2 to $11.4 \mu \mathrm{g} \mathrm{g}^{-1}$, and each 


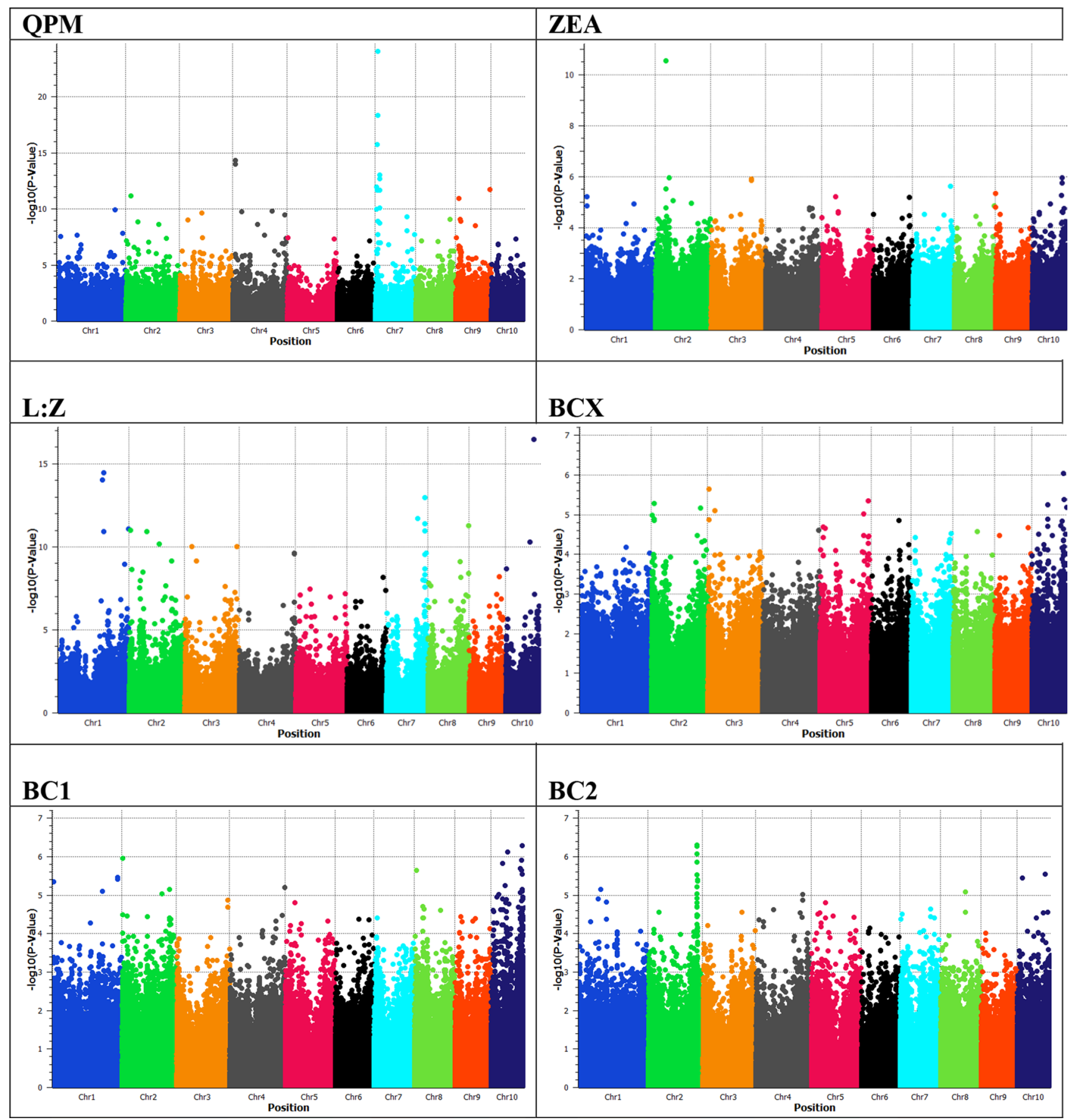

Fig. 2 GWAS manhattan plots using the mixed linear $(\mathrm{G}+\mathrm{Q}+\mathrm{K})$ model and the $55 \mathrm{~K}+$ GBS combined genotype data. $Q P M$ quality protein maize (binary phenotype), $Z E A$ zeaxanthin, $L: Z$ lutein:zeaxanthin ratio, $B C X \beta$-cryptoxanthin, $B C 1 \beta$-carotene, $B C 2$

explained 3-6 \% ZEA variation. A SNP on chromosome 7 (S7_160069429) was located close to GGPS2, which is an upstream gene involved in carotenoid metabolism. Two regions on chromosomes 5 and 7 (S5_196023723 and S7_124945321) identified in the rare allele analyses were distinctly different because of their large and positive $\beta$-carotene with the S10_135911532 marker as an additional covariate in the model. All carotenoids' phenotypic values $(y)$ were transformed to $\log _{10}(y+1)$ prior to analyses

contribution of minor allele towards ZEA concentration. A linear model with six candidate SNPs from $P$ value and rare allele based analyses explained close to $54 \%$ of phenotypic variance for ZEA (Table 2).

The seven significant regions for lutein:zeaxanthin ratio (L:Z) were distributed on chromosomes 1, 3, 7, 8, and 9 
Table 1 The list of significant genomic regions identified through GWAS analyses for each of the component carotenoid trait

\begin{tabular}{|c|c|c|c|c|c|c|c|c|c|c|}
\hline Trait/marker & $\mathrm{Chr}$ & $\begin{array}{l}\text { Position } \\
(\mathrm{Mb})^{\mathrm{a}}\end{array}$ & $\begin{array}{l}\text { Minor } \\
\text { allele }\end{array}$ & MAF & $\begin{array}{l}\text { FELM } \\
p \text { value }\end{array}$ & $\begin{array}{l}\text { MLM } \\
p \text { value }\end{array}$ & $\begin{array}{l}\text { Phenotype } \\
\text { effect } \\
\text { (DD-dd) }\end{array}$ & $R^{2}$ & No. of SNPs ${ }^{\mathrm{b}}$ & $\begin{array}{l}\text { Nearby } \\
\text { carotenoid } \\
\text { gene }^{c}\end{array}$ \\
\hline \multicolumn{11}{|l|}{$\beta C$} \\
\hline S10_135911532 & 10 & 135.9 & A & 0.34 & $1.73 \mathrm{E}-04$ & $5.05 \mathrm{E}-07$ & 2.11 & 0.07 & 6 & CRTRBI \\
\hline S8_8887117 & 8 & 8.9 & G & 0.07 & $2.20 \mathrm{E}-06$ & $2.23 \mathrm{E}-06$ & -1.07 & 0.06 & 1 & \\
\hline S10_71741924 & 10 & 71.7 & $\mathrm{~T}$ & 0.03 & $6.71 \mathrm{E}-08$ & $7.54 \mathrm{E}-07$ & 10.94 & 0.06 & 3 & \\
\hline S10_133820657 & 10 & 133.8 & $\mathrm{C}$ & 0.02 & $6.70 \mathrm{E}-09$ & $1.23 \mathrm{E}-06$ & 11.65 & 0.06 & 1 & CRTRB1 \\
\hline S10_134655704 & 10 & 134.7 & $\mathrm{C}$ & 0.03 & 5.13E-09 & $2.20 \mathrm{E}-06$ & 11.64 & 0.06 & 2 & CRTRB1 \\
\hline S1_280088079 & 1 & 280.1 & G & 0.03 & $3.87 \mathrm{E}-06$ & $3.40 \mathrm{E}-06$ & 2.26 & 0.06 & 6 & \\
\hline S2_212648728 & 2 & 212.6 & A & 0.04 & - & $4.86 \mathrm{E}-07$ & 2.98 & 0.16 & 20 & \\
\hline \multicolumn{11}{|l|}{$\beta C X$} \\
\hline S10_137426599 & 10 & 137.4 & A & 0.09 & $1.58 \mathrm{E}-05$ & $4.11 \mathrm{E}-06$ & -1.68 & 0.06 & 1 & CRTRBI \\
\hline S5_203698331 & 5 & 203.7 & $\mathrm{~T}$ & 0.32 & 4.95E-05 & 4.49E-06 & -1.36 & 0.06 & 1 & \\
\hline S2_9365226 & 2 & 9.4 & G & 0.14 & $2.86 \mathrm{E}-07$ & $5.08 \mathrm{E}-06$ & -1.28 & 0.06 & 3 & \\
\hline S10_67113044 & 10 & 67.1 & A & 0.35 & $2.24 \mathrm{E}-07$ & $5.58 \mathrm{E}-06$ & -1.18 & 0.05 & 3 & \\
\hline S10_146965726 & 10 & 147.0 & $\mathrm{C}$ & 0.05 & $7.86 \mathrm{E}-05$ & $6.48 \mathrm{E}-06$ & -2.03 & 0.05 & 1 & \\
\hline S2_207044142 & 2 & 207.0 & $\mathrm{C}$ & 0.12 & $6.62 \mathrm{E}-06$ & $6.68 \mathrm{E}-06$ & 1.46 & 0.05 & 1 & GGPS1 \\
\hline S3_30009999 & 3 & 30.0 & G & 0.30 & $1.23 \mathrm{E}-05$ & $7.83 \mathrm{E}-06$ & -1.08 & 0.05 & 1 & \\
\hline S5_184160168 & 5 & 184.2 & $\mathrm{~T}$ & 0.30 & $1.13 \mathrm{E}-04$ & $9.32 \mathrm{E}-06$ & 0.66 & 0.05 & 4 & \\
\hline S2_16916669 & 2 & 16.9 & $\mathrm{C}$ & 0.14 & $4.86 \mathrm{E}-03$ & $1.04 \mathrm{E}-03$ & 2.45 & 0.03 & 1 & HYD1 \\
\hline S9_151998412 & 9 & 152.0 & A & 0.05 & $5.39 \mathrm{E}-04$ & $2.95 \mathrm{E}-03$ & 2.47 & 0.02 & 1 & $\begin{array}{l}\text { CCD1/ } \\
\text { HYD5 }\end{array}$ \\
\hline S10_133820657 & 10 & 133.8 & $\mathrm{C}$ & 0.02 & $2.86 \mathrm{E}-08$ & $9.14 \mathrm{E}-07$ & -2.27 & 0.06 & 1 & CRTRB1 \\
\hline S3_5777896 & 3 & 5.8 & $\mathrm{C}$ & 0.04 & $1.86 \mathrm{E}-04$ & $2.23 \mathrm{E}-06$ & -1.68 & 0.06 & 2 & \\
\hline S6_146033807 & 6 & 146.0 & G & 0.03 & $7.27 \mathrm{E}-04$ & $1.23 \mathrm{E}-03$ & 3.14 & 0.03 & 3 & DXS1 \\
\hline \multicolumn{11}{|l|}{ ZEA } \\
\hline S2_44448492 & 2 & 44.4 & G & 0.31 & $1.85 \mathrm{E}-14$ & $2.77 \mathrm{E}-11$ & -5.12 & 0.11 & 3 & $Z E P 1$ \\
\hline S2_57643868 & 2 & 57.6 & G & 0.06 & 3.07E-07 & $1.04 \mathrm{E}-06$ & -4.98 & 0.06 & 1 & \\
\hline S3_172381448 & 3 & 172.4 & $\mathrm{C}$ & 0.07 & $4.78 \mathrm{E}-08$ & $1.20 \mathrm{E}-06$ & -5.22 & 0.06 & 3 & \\
\hline S9_566438 & 9 & 0.6 & $\mathrm{G}$ & 0.05 & $5.36 \mathrm{E}-06$ & $4.38 \mathrm{E}-06$ & -5.19 & 0.06 & 3 & \\
\hline S10_125724462 & 10 & 125.7 & $\mathrm{C}$ & 0.05 & 4.07E-07 & $5.29 \mathrm{E}-06$ & -5.31 & 0.05 & 2 & \\
\hline S1_8945297 & 1 & 8.9 & $\mathrm{~T}$ & 0.47 & $3.44 \mathrm{E}-06$ & $5.76 \mathrm{E}-06$ & -1.94 & 0.05 & 3 & \\
\hline S6_154891169 & 6 & 154.9 & $\mathrm{C}$ & 0.11 & $9.95 \mathrm{E}-06$ & $6.24 \mathrm{E}-06$ & -4.09 & 0.05 & 1 & \\
\hline S9_133887810 & 9 & 133.9 & G & 0.05 & $2.22 \mathrm{E}-04$ & $3.75 \mathrm{E}-03$ & 9.41 & 0.02 & 4 & \\
\hline S9_151998412 & 9 & 152.0 & A & 0.05 & $3.5 \mathrm{E}-04$ & $9.95 \mathrm{E}-03$ & 2.86 & 0.02 & 1 & $\begin{array}{l}\text { CCDI/ } \\
\text { HYD5 }\end{array}$ \\
\hline S10_126915113 & 10 & 126.9 & G & 0.04 & $6.19 \mathrm{E}-09$ & $1.06 \mathrm{E}-06$ & -6.03 & 0.06 & 3 & \\
\hline S7_160069429 & 7 & 160.1 & A & 0.03 & $1.03 \mathrm{E}-06$ & $2.24 \mathrm{E}-06$ & -5.63 & 0.06 & 1 & GGPS2 \\
\hline S5_58706973 & 5 & 58.7 & G & 0.03 & $1.49 \mathrm{E}-04$ & $5.91 \mathrm{E}-06$ & -5.27 & 0.05 & 1 & \\
\hline S5_196023723 & 5 & 196.0 & G & 0.03 & $3.45 \mathrm{E}-05$ & $4.31 \mathrm{E}-04$ & 10.37 & 0.03 & 11 & \\
\hline S7_124945321 & 7 & 124.9 & A & 0.03 & $4.45 \mathrm{E}-04$ & $9.29 \mathrm{E}-04$ & 11.44 & 0.03 & 1 & \\
\hline \multicolumn{11}{|l|}{ L:Z } \\
\hline S1_175591561 & 1 & 175.6 & A & 0.49 & 4.37E-05 & $9.78 \mathrm{E}-03$ & -0.41 & 0.02 & 2 & \\
\hline S9_130410559 & 9 & 130.4 & $\mathrm{C}$ & 0.13 & $2.04 \mathrm{E}-04$ & $1.81 \mathrm{E}-03$ & -0.38 & 0.03 & 2 & \\
\hline S7_143524503 & 7 & 143.5 & $\mathrm{C}$ & 0.18 & $3.08 \mathrm{E}-03$ & $6.69 \mathrm{E}-03$ & -0.36 & 0.02 & 9 & \\
\hline S3_141214784 & 3 & 141.2 & $\mathrm{~T}$ & 0.34 & $2.11 \mathrm{E}-04$ & $8.72 \mathrm{E}-04$ & -0.37 & 0.04 & 2 & \\
\hline S1_296844851 & 1 & 296.8 & $\mathrm{C}$ & 0.04 & $9.85 \mathrm{E}-08$ & 7.97E-12 & 5.26 & 0.15 & 5 & \\
\hline S8__138523563 & 8 & 138.5 & A & 0.03 & $4.25 \mathrm{E}-14$ & $7.25 \mathrm{E}-10$ & 2.43 & 0.12 & 1 & LCYE \\
\hline
\end{tabular}

$\beta C \beta$-carotene, $\beta C X \beta$-cryptoxanthin, $Z E A$ zeaxanthin, $L: Z$ lutein:zeaxanthin ratio, $C h r$ chromosome, $M A F$ minor allele frequency, $F E L M$ fixed effect linear model, $M L M$ mixed linear model, $D D$ homozygous-minor-allele genotype, $d d$ homozygous-major-allele genotype

a The exact physical position of the SNP can be inferred from marker's name, for example, S10_135911532: chromosome 10; 135,911,532 bp

b Number of significant SNPs within a $500 \mathrm{~kb}$ window

c The nearest previously identified carotenoid-pathway-related gene 
Table 2 Multiple linear regressions of carotenoids $(y)$ using selected SNPs $(x)$ based on MLM $p$ values and rare allele analysis

\begin{tabular}{llllrrr}
\hline Trait & $\begin{array}{l}\text { Candidate SNP } \\
\text { analysis }^{\mathrm{a}}\end{array}$ & $\begin{array}{l}\text { No. of SNPs in } \\
\text { the model }^{\mathrm{b}}\end{array}$ & No. of lines & F & $P$ value & Adjusted $R^{2}$ \\
\hline$\beta C$ & MLM & 5 & 122 & 39.58 & $<0.01$ & 0.61 \\
$\beta C X$ & MLM & 4 & 176 & 19.46 & $<0.01$ & 0.30 \\
& Rare allele & 3 & 112 & 22.03 & $<0.01$ & $<0.01$ \\
ZEA & MLM & 6 & 109 & 11.55 & $<0.01$ & 0.17 \\
& Rare allele & 3 & 268 & 65.24 & $<0.01$ & 0.14 \\
L:Z & MLM & 1 & 121 & 6.65 & $<0.01$ & 0.35 \\
& Rare allele & 3 & 150 & & 0.22 \\
\hline
\end{tabular}

$\beta C \beta$-carotene, $\beta C X \beta$-cryptoxanthin, $Z E A$ zeaxanthin, $L: Z$ lutein:zeaxanthin ratio, $M L M \mathrm{G}+\mathrm{Q}+\mathrm{K}$ model

${ }^{a}$ Analysis from which 10 candidate SNPs selected

b Number of SNPs in the final models resulted from further selection using stepwise approach based on AIC values

(Table 1). A SNP on chromosome 8 (S8_138523563) was located within $500 \mathrm{~kb}$ of the $L C Y E$ gene and explained $12 \%$ of phenotypic variance for L:Z. In five of the seven genomic regions, minor allele had favorable effect of lowering the L:Z ratio. Low minor allele frequency with large negative effects (difference between phenotypic averages of minor and major allele) for L:Z ratio are desired for proVA breeding because they represent opportunities to increase flux to the $\beta$ branch of the carotenoid pathway (Fig. S1).

\section{Discussion}

Genotype by environment interaction (GEI) effects can influence QTL and association mapping results, requiring the effect of identified genomic regions to be estimated for each environment (Zhang et al. 2008; Tétard-Jones et al. 2012). In the current investigation, the correlation coefficients among environments were highly significant (Table S3), indicating a minor role of GEI towards expression of most of the carotenoid component traits, as previously shown by Suwarno et al. (2014).

The phenotypic correlation coefficients among different component carotenoids were generally as expected based on their known relationships in the carotenoid biosynthetic pathway (Farré et al. 2010). Lutein, which is on the $\alpha$-branch, was not significantly associated with $\beta C$ or $\beta C X$ which are on the $\beta$ branch (Fig. 1). The significant correlation between LUT and ZEA $(r=0.38, P<0.01)$ suggests that these traits increase or decrease in parallel for genotypes with more or less total flux through the carotenoid pathway. There was a strong relationship between $\beta \mathrm{CX}$ and ZEA $(r=0.65$, $P<0.01$ ), indicating significant consistency in the rate of bioconversion of the former to the latter, which is located downstream in the $\beta$-branch of the pathway (Fig. S1).

The extent of LD in any given association panel has profound influence on GWAS results because larger LD blocks and slower rate of LD decay generally result in lower mapping resolution. We found rapid LD decay $(\sim 1.4 \mathrm{~kb}$, $\left.r^{2}=0.2\right)$ in CIMMYT's predominantly tropical and subtropical CAM panel using GBS data, which however varied among different chromosomes (Figure S5). A recent study using GBS data for 2,815 inbred lines from worldwide maize breeding programs found $\mathrm{LD}$ of $1 \mathrm{~kb}$, for tropical germplasm and $10 \mathrm{~kb}$, for temperate maize (Romay et al. 2013). Lu et al. (2011) estimated considerably larger LD of 5-10 kb, and 10-100 kb for tropical and temperate germplasm, respectively, using Illumina's golden gate genotyping platform, which used a much smaller number $(1,943$ SNPs) of markers relative to GBS. These studies indicated that LD decayed faster in tropical than in temperate germplasm, suggesting a wider genetic base resulting from more generations of divergence in tropical germplasm. As a consequence, higher mapping resolution using tropical germplasm is expected. Fewer markers should result in more unrepresented genomic regions, whereas more SNPs from the GBS platform should aid in the more precise estimation of LD decay distance and finer delimitation of genomic intervals for the carotenoid traits.

Most of the significant association signals for $\beta C$ in our study pointed to CRTRBI on chromosome 10 , which is known to play a significant role in enhancing $\beta \mathrm{C}$ content in a range of temperate and tropical germplasm (Yan et al. 2010; Babu et al. 2013). This result may have been driven by the inclusion of $10 \mathrm{~S} 2$ or $\mathrm{S} 3$ lines in the CAM panel which are CRTRBI introgressions and have average $\beta C$ concentrations significantly larger than the population mean. However, the finding that the delimited genomic region was very large may have been due to smaller number of recombinations and consequently larger CRTRBI introgression blocks in these early generation lines. A localized LD analysis in the CRTRB1 genomic region (133$136.5 \mathrm{Mb}$ ) confirmed the above inference, which revealed higher LD levels $\left(R^{2}=0.86, D^{\prime}=0.97\right)$ as compared to 
the genome-wide average $\left(R^{2}=0.41, D^{\prime}=0.81\right)$. By comparison, GWAS analysis for the binary QPM trait using the panel's 19 quality protein maize (QPM) inbred lines, which were derived through multiple rounds of selfing, identified the opaque 2 gene (chromosome 7: $10.79 \mathrm{Mb}$ ) with a resolution of $\sim 200 \mathrm{~Kb}$.

By controlling the variation explained by CRTRBI, we identified a significant region on chromosome 2 $\left(\mathrm{S} 2 \_212648728, \mathrm{MAF}=0.04\right)$ that explained $16 \%$ of phenotypic variance for $\beta C$ and the the minor allele had a favorable effect of $\sim 3 \mu \mathrm{g} \mathrm{g}^{-1}$. This SNP is located within the Amelogenin gene (chromosome 2: 212,648,384$212,649,098$ ) and nearby the $40 \mathrm{~S}$ ribosomal protein S9 gene (chromosome 2: 212,644,796-212,647,696). Seven of eight donor lines identified for this region were different from those for CRTRB1 and belonged to diverse backgrounds including tropical, subtropical and temperate germplasm. The 40S ribosomal protein S9 gene has larger expression $(\mathrm{FPKM}=2104.3)$ than that of CRTRB1 $(\mathrm{FPKM}=1148.5)$ in the endosperm at 16 days after pollination (DAP) (Sekhon et al. 2013). These results suggest potential value as an additional target region for enhanced $\beta \mathrm{C}$ content in proVA breeding programs subject to validation in bi-parental or other independent association populations.

For $\beta C X$, two of the 13 associations identified surrounded the CRTRBI region on chromosome 10 and the minor allele at these loci reduced the $\beta C X$ content by $1.7-2.3 \mu \mathrm{g} \mathrm{g}^{-1}$. CRTRB1 specifically controls hydroxylation of $\beta C$ to $\beta C X$ in maize endosperm tissues, and its alleles with reduced hydroxylation activity are associated with increased $\beta C$ and decreased $\beta C X$ content (Vallabhaneni et al. 2009; Yan et al. 2010; Babu et al. 2013). The minor alleles at eight of the detected associations decreased the $\beta C X$ content, whereas they had an enhancing effect at the rest of the five regions. Interestingly, four of the five regions, in which minor alleles had a favorable trait enhancing effect overlapped with five candidate genes viz., GGPS1, HYD1, CCD1, HYD5 and DXS1, all of which have been previously demonstrated to be associated with carotenoid metabolism.

The maize genome has two types of carotene hydroxylases - one each of the P450 heme-thiolate CYP97A and CYP97C, and six unlinked paralogs of non-heme di-iron carotene hydroxylases (HYD) (Vallabhaneni et al. 2009). HYD5 encodes an enzyme with hydroxylase domains and plastid-targeting signals, and its role has been suggested to be in the conversion of $\beta C X$ to ZEA (Sun et al. 1996). If alleles of HYD5 indeed reduce the hydroxylation of $\beta C X$ to ZEA, they may present opportunities to enhance $\beta C X$ and proVA concentration. Dhliwayo et al. (2014) discuss evidence that $\beta C X$ has greater nutritional value, including proVA value, than commonly reported and therefore, selecting for $\beta C$-enhancing alleles of CRTRB1 may be less desirable than a strategy of selecting for alleles that favor increased accumulation of $\beta C X$. Much research is needed to understand the specific roles of the carotene hydroxylase paralogs in the regulation of carotenoid biosynthesis and whether they may offer opportunities for breeding enhanced proVA concentrations.

By functional associations of QTL detected in two maize populations, Kandianis et al. (2013) recently concluded that total carotenoid concentration is influenced by the allocation of carbon substrates to the carotenoid pathway and by the removal of carotenoids through $C C D 1$ facilitated catabolism or ZEP-mediated conversion. Joint linkage analysis for visually scored kernel color intensity in ten NAM (nested association mapping) populations also revealed QTL on chromosomes 2 and 9 that coincided with ZEP1 and CCDI (Chandler et al. 2013). Vallabhaneni and Wurtzel (2009) previously established that the ZEP genes affect the conversion of ZEA to violaxanthin (a precursor of abscisic acid in maize endosperm) and negatively correlate with total carotenoid accumulation in maize endosperm. The most significant SNP for ZEA in our study resided inside the ZEPI gene on chromosome 2 (Table 1); replacing the unfavorable minor allele of ZEPI with the favorable one, therefore, may benefit many lines. A recent GWAS study in an inbred association panel of 281 lines ranging from light yellow to deep orange identified genomic variations within the coding region of ZEPI as one of the important determinants of seed carotenoid content, besides LUT1, LUT5 and DXS2 (Owens et al. 2014).

Two other genes that have been implicated in carotenoid metabolism (Wurtzel et al. 2012), GGPS2 (on chromosome 7) and DXSI (on chromosome 6), are located in the vicinity of the 10 most significant associations that we found for ZEA (GGPS2) and $\beta C X(D X S 1)$. Deoxyxylulose synthase $(D X S)$, together with deoxyxylulose reductase convert the three-carbon molecules from glycolysis to methyl-erythrol phosphate (MEP) (Fig. S1). The MEP pathway synthesizes isoprenoids through different enzymatic reactions including GGPS, producing GGPP, the isoprenoid substrate for carotenoid biosynthesis (Fig. S1). Notably, in the current study, the minor allele for GGPS2 was the unfavorable one (decreasing the ZEA content by $\sim 6 \mu \mathrm{g} \mathrm{g}^{-1}$ ), indicating the prevalence of favorable alleles in the CAM panel. On the other hand, the minor allele for DXS1 was the favorable one (increasing the $\beta C X$ content by $\sim 3 \mu \mathrm{g} \mathrm{g}^{-1}$ ), and there are eight lines in the panel having homozygous favorable allele for this gene (Table S5).

The mechanisms regulating carotenoid content, including localization of carotenoid biosynthetic enzymes in amyloplasts, carotenoid catabolism and degradation are not well understood (Shumskaya and Wurtzel 2013; De Moura et al. 2013). Catabolism of carotenoids plays an important role, at least in photosynthetic tissues, to help 
maintain carotenoids at physiologically important levels. Although non-enzymatic degradation of carotenoids also occurs, catabolism mediated by the carotenoid cleavage enzymes (CCD1, CCD4, CCD7 and CCD8) and the 9-cisepoxycarotenoid dioxygenases (NCED2, NCED3, NCED5, NCED6 and NCED9) in seeds affect carotenoid composition and content (Gonzalez-Jorge et al. 2013). CCD family genes have been shown to deplete the carotenoid pool in Arabidopsis seeds, chrysanthemum flowers and strawberries (Auldridge et al. 2006; Ohmiya et al. 2006; Vogel et al. 2008; García-Limones et al. 2008; Gonzalez-Jorge et al. 2013). In maize endosperm, correlation of CCD1 transcript abundance with lower levels of carotenoids and a pronounced dosage effect resulting from copy number variation has been reported (Vallabhaneni et al. 2010). In addition, genotypic variation on the transcript profiles not only of $C C D 1$ but also of other carotenoid catabolic enzymes, CCD4, CCD7, NCED1 and NCED9 was observed in maize endosperm (Vallabhaneni et al. 2010). Genotypic variation has also been observed for the degradation rate of proVA carotenoids in maize; $40-70 \%$ proVA loss has been recorded among 10 lines and hybrids after storage for 4 months at tropical ambient conditions (N. Palacios-Rojas, unpublished data).

14 significant genomic regions were identified for ZEA concentration, of which five were rare allele type associations. The confidence interval of one of the associations on chromosome 9 (S9_151998412) contained CCD1 [linked to $W C 1$ locus (White Cap 1)]. We identified 11 lines that possess a native variation linked to CCDI on chromosome 9 (Table S6). Interestingly, one of these 11 lines is very closely related to other lines previously identified as "low degradation lines" based on observations of proVA loss during storage. In addition, experimental hybrids with some of the lines identified here with the native variation for $C C D 1$ in their pedigrees have also shown reduced loss of proVA (10-15\%) during one month storage compared to other hybrids that lost up to $36 \%$ of proVA (N. PalaciosRojas, unpublished data). Other than CCD1-related association, three regions on chromosomes 5, 7 and 9 appeared interesting, whose minor alleles had large positive effects on ZEA concentration ranging from 9.4-11.4 $\mu \mathrm{g} \mathrm{g}^{-1}$.

Gonzalez-Jorge et al. (2013), using linkage mapping and GWAS for seed carotenoid content identified that the plastid-localized $C C D 4$ is a major determinant while $C C D 1$ has a limited contribution to dry seed $\beta C$ retention in Arabidopsis. If such a relationship holds true for maize it could help explain the association between $\beta C X$ and $C C D 1$ in our study (Table 2) if, for example, $C C D 1$ cleaves ZEA preferentially to $\beta C$ and $\beta C X$. Upon validation of the favorable alleles of $C C D 1$ and other three candidate associations for enhanced ZEA concentration in appropriate bi-parental populations, they could be useful in proVA biofortification breeding programs as donor lines for minimizing carotenoid catabolism as well as enhancing the total flux into the $\beta$ - branch of the pathway.

One of the significant markers for L:Z ratio (S8_138523563) was very closely linked to $L C Y E$, which has a significant effect on relative carotenoid concentrations in the $\alpha$-versus $\beta$-branches of the carotenoid pathway (Harjes et al. 2008). Other than this, four genomic regions were identified wherein the minor allele had a favorable effect of reduced L:Z ratio. The effect of these minor alleles and consequent value for selection in breeding programs requires validation in appropriate bi-parental populations. Altering the L:Z ratio, however, will not necessarily achieve the desired effect on total proVA concentration as evidenced by reports that both the $\alpha$ - and $\beta$-branches can be "over loaded," resulting in feedback inhibition to total flux into the carotenoid pathway (Babu et al. 2013; Arango et al. 2014).

Besides $P$ value based most significant associations for each of the carotenoid traits, we have identified rare alleles (MAF $<0.05$ but $>0.02$ ) that have large and favorable phenotypic effects in this study. These candidate associations are detected with less statistical power (as compared to top most $P$ value based associations) but nevertheless help in identification of smaller set of candidates that could be validated in subsequent studies using bi-parental populations. GWAS based on common variants tend to ignore such rare alleles, which are now being speculated to play a crucial role in addressing the missing heritability issue (Stranger et al. 2011). We propose a four-step sequential strategy for identification and verification of such rare allele associations-(1) identify the rare variant associations at certain threshold significance (we adopted MLM-P $<0.01$ as nominal), (2) filter based on effect size (30\% more favorable than the population average for the trait), (3) prioritize large-effect rare variants based on evidences such as underlying candidate genes that were previously shown to be associated with the trait in either maize or other model species, and (4) identify or create suitable bi-parental populations that segregate for candidate rare variant associations and validate the phenotypic effect. Such an approach is especially relevant when the frequency of desired trait occurrence, for instance, enhanced carotenoid concentrations in our study, in the association panel is less. In the carotenoid panel that we examined, average proVA concentration was around $4 \mu \mathrm{g} \mathrm{g}^{-1}$ and only 16 out of the $\sim 380$ lines (less than $5 \%$ ) possessed proVA concentrations of above $8 \mu \mathrm{g} \mathrm{g}^{-1}$.

A genome-wide atlas documenting different spatial and temporal patterns of transcription of genes has been developed for maize using microarrays and RNA sequencing (Sekhon et al. 2011; Hansey et al. 2012; Sekhon et al. 2013). Comparison of the significant associations 
discovered in the current study with endosperm expression values of genes at 16 DAP (Sekhon et al. 2013) revealed at least 24 genes that were expressed, of which four (CRTRB1, GGPS1, GGPS2, and CCD1) are involved in carotenoid metabolism (Table S7). One or more of the remaining 20 genes might be important through epistatic effects on carotenoid pathway genes, for example the $40 \mathrm{~S}$ ribosomal protein S9 gene.

The ability of multiple linear regression models to explain large proportions of the phenotypic variances (Table 2) suggests that simple assays involving a small number of SNPs could be designed for selecting lines with favorable alleles for carotenoids concentrations.

\section{Conclusions}

GWAS suggested several genes that are not within the carotenoid pathway but may affect carotenoids concentrations, validated the significance of CRTRB1, and identified hydroxylase genes (such as HYD5 and HYDI) and favorable native genomic variations that may help achieve higher amounts of nutritionally useful carotenoids. Detection of significant association signals in the current investigation pertaining to other candidate genes such as GGPS2, DXS1, ZEP1, and CCDI support the possibility of increasing proVA in maize by selecting for alleles that enhance the total biochemical flux towards carotenoid biosynthesis or arrest carotenoid catabolism in the pathway. Unfortunately, although perhaps promising for other proVA breeding programs, opportunities to enhance total flux by selecting favorable alleles of GGPS 2 and ZEP1 appear limited in the germplasm represented by CIMMYT's CAM panel, where the favorable alleles are already in high frequency. Focus on reduced carotenoid catabolism by selecting favorable alleles of $C C D 1$, however, could contribute to proVA biofortification strategies and native genomic variations at or close to these loci have been characterized and corresponding donor lines identified for possible use in maize breeding programs aimed at carotenoid biofortification. Future research is also warranted to validate the effects and explore the utility of selecting for genes whose increased expression rates (reported by Sekhon et al. 2013) were associated with minor alleles that favorably affected carotenoids concentrations in CIMMYT's CAM panel.

Author contribution statement $\mathrm{RB}, \mathrm{KP}$ and $\mathrm{NP}-$ conceived the experiment; $\mathrm{NP}$ and $\mathrm{KP}$ - conducted the field evaluations and carotenoid phenotyping; RB-coordinated the $55 \mathrm{~K}$ and GBS experiments; WBS and RB - carried out the GWAS analyses; RB, WBS, KP, NP and SMK-interpreted the results and drafted the manuscript.
Acknowledgments This research was supported by HarvestPlus (www.harvestplus.org), an international program that develops micronutrient-rich staple food crops to reduce hidden hunger among malnourished populations. We thank the partial funding support received from MAIZE CRP W1/W2 towards carotenoid phenotyping. We extend our gratitude to Syngenta Foundation for Sustainable Agriculture (SFSA) and Syngenta, USA for having sponsored and conducted $55 \mathrm{~K}$ genotyping using Illumina's Infinium Platform. We thank Dr. Edward S Buckler and the Institute of Genomic Diversity, Cornell University for the high-density genotyping (GBS) and imputation service. We thank Thanda Dhliwayo, Germán Mingramm, and José Luis Coyac for their support towards field activities, the staff at CIMMYT research stations for managing the trials, and the staff at CIMMYT's maize quality laboratory for carrying out the carotenoid analyses. Additional support provided by the Directorate General of Higher Education of Indonesia is highly appreciated.

Conflict of interest The authors declare that they have no conflict of interest.

Open Access This article is distributed under the terms of the Creative Commons Attribution License which permits any use, distribution, and reproduction in any medium, provided the original author(s) and the source are credited.

\section{References}

Arango J, Jourdan M, Geoffriau E, Beyer P, Welsch R (2014) Carotene hydroxylase activity determines the levels of both $\alpha$-carotene and total carotenoids in orange carrots. Plant Cell 26:2223-2233. doi:10.1105/tpc.113.122127

Atlin GN, Palacios N, Babu R, Das B, Twumasi-Afriyie S, Friesen DK, De Groote H, Vivek B, Pixley KV (2011) Quality protein maize: progress and prospects. Plant Breed Rev. doi:10.1002/9780470880579.ch3

Auldridge ME, Block A, Vogel JT, Dabney-Smith C, Mila I, Bouzayen M, Magallanes-Lundback M, DellaPenna D, McCarty DR, Klee HJ (2006) Characterization of three members of the arabidopsis carotenoid cleavage dioxygenase family demonstrates the divergent roles of this multifunctional enzyme family. Plant $\mathrm{J}$ 45:982-993. doi:10.1111/j.1365-313X.2006.02666.x

Babu R, Rojas NP, Gao S, Yan J, Pixley K (2013) Validation of the effects of molecular marker polymorphisms in LcyE and CrtRB1 on provitamin A concentrations for 26 tropical maize populations. Theor Appl Genet 126:389-399. doi:10.1007/s00122-012-1987-3

Bishop DT, Williamson JA (1990) The power of identity-by-state methods for linkage analysis. Am J Hum Genet 46:254-265

Chandler K, Lipka AE, Owens BF, Li H, Buckler ES, Rocheford T, Gore MA (2013) Genetic analysis of visually scored orange kernel color in maize. Crop Sci 53:189. doi:10.2135/ cropsci2012.02.0129

Core Team R (2012) R: a language and environment for statistical computing. R Foundation for Statistical Computing, Vienna

De Moura FF, Miloff A, Boy E (2013) Retention of provitamin A carotenoids in staple crops targeted for biofortification in Africa: cassava, maize and sweet potato. Crit Rev Food Sci Nutr null. doi $: 10.1080 / 10408398.2012 .724477$

Dhliwayo T, Palacios-Rojas N, Crossa J, Pixley K (2014) Effects of S1 recurrent selection for provitamin-A carotenoid content for three open-pollinated maize cultivars. Crops. Org. doi:10.2135/ cropsci2013.11.0764 
Elshire RJ, Glaubitz JC, Sun Q, Poland JA, Kawamoto K, Buckler ES, Mitchell SE (2011) A robust, simple genotyping-by-sequencing (GBS) approach for high diversity species. PLoS ONE 6:e19379. doi:10.1371/journal.pone.0019379

Farré G, Sanahuja G, Naqvi S, Bai C, Capell T, Zhu C, Christou P (2010) Travel advice on the road to carotenoids in plants. Plant Sci 179:28-48. doi:10.1016/j.plantsci.2010.03.009

Galicia L, Nurit E, Rosales A, Palacios-Rojas N (2008) Maize nutrition quality and plant tissue analysis laboratory

Galicia L, Rosales A, Gutierrez G, Custodio O, Miranda A, Ruiz N, Surles R, Palacios-Rojas N (2012) Manual de laboratorio de calidad nutricional de maíz. CIMMYT, Mexico

García-Limones C, Schnäbele K, Blanco-Portales R, Luz Bellido M, Caballero JL, Schwab W, Muñoz-Blanco J (2008) Functional characterization of FaCCD1: a carotenoid cleavage dioxygenase from strawberry involved in lutein degradation during fruit ripening. J Agric Food Chem 56:9277-9285. doi:10.1021/jf801096t

Gibson G (2010) Hints of hidden heritability in GWAS. Nat Genet 42:558-560. doi:10.1038/ng0710-558

Giuliano G, Tavazza R, Diretto G, Beyer P, Taylor MA (2008) Metabolic engineering of carotenoid biosynthesis in plants. Trends Biotechnol 26:139-145. doi:10.1016/j.tibtech.2007.12.003

Gonzalez-Jorge S, Ha SH, Magallanes-Lundback M, Gilliland LU, Zhou A, Lipka AE, Nguyen YN, Angelovici R, Lin H, Cepela J, Little H, Buell CR, Gore MA, DellaPenna D (2013) Carotenoid cleavage dioxygenase 4 is a negative regulator of $\beta$-carotene content in arabidopsis seeds. Plant Cell Online 25:4812-4826. doi:10.1105/tpc.113.119677

Graham RD, Welch RM, Bouis HE (2001) Addressing micronutrient malnutrition through enhancing the nutritional quality of staple foods: principles, perspectives and knowledge gaps. Adv Agron 70:77-142. doi:10.1016/S0065-2113(01)70004-1

Hansey CN, Vaillancourt B, Sekhon RS, de Leon N, Kaeppler SM, Buell CR (2012) Maize (Zea mays L.) genome diversity as revealed by RNA-sequencing. PLoS One 7:e33071. doi:10.1371/ journal.pone.0033071

Harjes CE, Rocheford TR, Bai L, Brutnell TP, Kandianis CB, Sowinski SG, Stapleton AE, Vallabhaneni R, Williams M, Wurtzel ET, Yan J, Buckler ES (2008) Natural genetic variation in lycopene epsilon cyclase tapped for maize biofortification. Science 319:330-333. doi:10.1126/science. 1150255

Hill WG, Weir BS (1988) Variances and covariances of squared linkage disequilibria in finite populations. Theor Popul Biol 33:54-78

Jombart T, Devillard S, Balloux F (2010) Discriminant analysis of principal components: a new method for the analysis of genetically structured populations. BMC Genet 11:94. doi:10.1186/1471-2156-11-94

Kandianis CB, Stevens R, Liu W, Palacios N, Montgomery K, Pixley K, White WS, Rocheford T (2013) Genetic architecture controlling variation in grain carotenoid composition and concentrations in two maize populations. Theor Appl Genet 126:2879-2895. doi:10.1007/s00122-013-2179-5

Li F, Tsfadia O, Wurtzel ET, Tzfadia O, Wurtzel ET (2009) The phytoene synthase gene family in the grasses: subfunctionalization provides tissue-specific control of carotenogenesis. Plant Signal Behav 4:208-211. doi:10.1104/pp.107.111120.and

Lu Y, Shah T, Hao Z, Taba S, Zhang S, Gao S, Liu J, Cao M, Wang J, Prakash AB, Rong T, Xu Y (2011) Comparative SNP and haplotype analysis reveals a higher genetic diversity and rapider LD decay in tropical than temperate germplasm in maize. PLoS One 6:e24861. doi:10.1371/journal.pone.0024861

Ohmiya A, Kishimoto S, Aida R, Yoshioka S, Sumitomo K (2006) Carotenoid cleavage dioxygenase (CmCCD4a) contributes to white color formation in chrysanthemum petals. Plant Physiol 142:1193-1201. doi:10.1104/pp.106.087130
Owens BF, Lipka AE, Magallanes-Lundback M, Tiede T, Diepenbrock $\mathrm{CH}$, Kandianis CB, Kim E, Cepela J, Mateos-Hernandez M, Buell CR, Buckler ES (2014) A foundation for provitamin A biofortification of maize: Genome-wide association and genomic prediction models of carotenoid levels. Genetics. doi:10.1534/ genetics.114.169979

Pixley K, Palacios NP, Babu R, Mutale R, Simpungwe E (2013) Biofortification of maize with provitamin A carotenoids. In: Tanumihardo SA (ed) Carotenoids, Human Health and Nutrition. Springer Science + Business Media, New York. doi:10.1007/978-1-62703-203-2_17

Price AL, Patterson NJ, Plenge RM, Weinblatt ME, Shadick NA, Reich D (2006) Principal components analysis corrects for stratification in genome-wide association studies. Nat Genet 38:904909. doi: $10.1038 / n g 1847$

Remington DL, Thornsberry JM, Matsuoka Y, Wilson LM, Whitt SR, Doebley J, Kresovich S, Goodman MM, Iv ESB (2001) Structure of linkage disequilibrium and phenotypic associations in the maize genome. 98:11479-11484

Romay MC, Millard MJ, Glaubitz JC, Peiffer JA, Swarts KL, Casstevens TM, Elshire RJ, Acharya CB, Mitchell SE, FlintGarcia SA, McMullen MD, Holland JB, Buckler ES, Gardner CA (2013) Comprehensive genotyping of the usa national maize inbred seed bank. Genome Biol 14:R55. doi:10.1186/ gb-2013-14-6-r55

Saltzman A, Birol E, Bouis HE, Boy E, De Moura FF, Islam Y, Pfeiffer WH (2013) Biofortification: progress toward a more nourishing future. Glob Food Sec 2:9-17. doi:10.1016/j. gfs.2012.12.003

Sekhon RS, Lin H, Childs KL, Hansey CN, Buell CR, de Leon N, Kaeppler SM (2011) Genome-wide atlas of transcription during maize development. Plant J 66:553-563. doi:10.1111/j.1365-313X.2011.04527.x

Sekhon RS, Briskine R, Hirsch CN, Myers CL, Springer NM, Buell CR, de Leon N, Kaeppler SM (2013) Maize gene atlas developed by rna sequencing and comparative evaluation of transcriptomes based on RNA sequencing and microarrays. PLoS One 8:e61005. doi:10.1371/journal.pone.0061005

Shumskaya M, Wurtzel ET (2013) The carotenoid biosynthetic pathway: thinking in all dimensions. Plant Sci 208:58-63. doi:10.1016/j.plantsci.2013.03.012

Stranger BE, Stahl EA, Raj T (2011) Progress and promise of genome-wide association studies for human complex trait genetics. Genetics 187:367-383. doi:10.1534/genetics.110.120907

Sun Z, Gantt E, Cunningham FX (1996) Cloning and functional analysis of the \& \#x03B2;-carotene hydroxylase of arabidopsis thaliana. J Biol Chem 271:24349-24352. doi:10.1074/ jbc.271.40.24349

Suwarno WB, Pixley KV, Palacios-Rojas N, Kaeppler SM, Babu R (2014) Formation of heterotic groups and understanding genetic effects in a provitamin A biofortified maize breeding program. Crop Sci 54:14. doi:10.2135/cropsci2013.02.0096

Tétard-Jones C, Kertesz MA, Preziosi RF (2012) Identification of plant quantitative trait loci modulating a rhizobacteria-aphid indirect effect. PLoS ONE 7:e41524. doi:10.1371/journal. pone.0041524

Vallabhaneni R, Wurtzel ET (2009) Timing and biosynthetic potential for carotenoid accumulation in genetically diverse germplasm of maize. Plant Physiol 150:562-572. doi:10.1104/ pp.109.137042

Vallabhaneni R, Gallagher CE, Licciardello N, Cuttriss AJ, Quinlan RF, Wurtzel ET (2009) Metabolite sorting of a germplasm collection reveals the hydroxylase 3 locus as a new target for maize provitamin A biofortification. Plant Physiol 151:1635-1645. doi:10.1104/pp.109.145177 
Vallabhaneni R, Bradbury LMT, Wurtzel ET (2010) The carotenoid dioxygenase gene family in maize, sorghum, and rice. Arch Biochem Biophys 504:104-111. doi:10.1016/j.abb.2010.07.019

Vogel JT, Tan B-C, McCarty DR, Klee HJ (2008) The carotenoid cleavage dioxygenase 1 enzyme has broad substrate specificity, cleaving multiple carotenoids at two different bond positions. J Biol Chem 283:11364-11373. doi:10.1074/jbc.M710106200

Weir BS (2008) Linkage disequilibrium and association mapping. Annu Rev Genomics Hum Genet 9:129-142. doi:10.1146/ annurev.genom.9.081307.164347

Wurtzel ET, Cuttriss A, Vallabhaneni R (2012) Maize provitamin A carotenoids, current resources, and future metabolic engineering challenges. Front Plant Sci 3:29. doi:10.3389/fpls.2012.00029
Xu JH, Messing J (2006) Maize haplotype with a helitronamplified cytidine deaminase gene copy. BMC Genet 7:52. doi:10.1186/1471-2156-7-52

Yan J, Kandianis CB, Harjes CE et al (2010) Rare genetic variation at Zea mays crtRB1 increases beta-carotene in maize grain. Nat Genet 42:322-327. doi:10.1038/ng.551

Zhang K, Tian J, Zhao L, Wang S (2008) Mapping QTLs with epistatic effects and QTL $\mathrm{x}$ environment interactions for plant height using a doubled haploid population in cultivated wheat. J Genet Genomics 35:119-127. doi:10.1016/S1673-8527(08)60017-X 